$\begin{array}{ll} & \text { Etnográfica } \\ \text { etnográfica } & \text { Revista do Centro em Rede de Investigação em }\end{array}$

Antropologia

vol. 17 (1) | 2013

Vol. $17(1)$

\title{
Procesos de revalorización patrimonial en el barrio de Alfama: el papel de los estudiantes Erasmus en la tematización de la ciudad
}

Patrimonial revaluation processes in Alfama neighbourhood (Lisbon): the role of Erasmus students in city thematization

\section{Daniel Malet Calvo}

\section{(2) OpenEdition}

\section{Journals}

\section{Edición electrónica}

URL: https://journals.openedition.org/etnografica/2532

DOI: 10.4000/etnografica.2532

ISSN: 2182-2891

\section{Editor}

Centro em Rede de Investigação em Antropologia

\section{Edición impresa}

Fecha de publicación: 1 febrero 2013

Paginación: 31-50

ISSN: 0873-6561

\section{Referencia electrónica}

Daniel Malet Calvo, «Procesos de revalorización patrimonial en el barrio de Alfama: el papel de los estudiantes Erasmus en la tematización de la ciudad», Etnográfica [En línea], vol. 17 (1) | 2013, Publicado el 13 marzo 2013, consultado el 11 febrero 2022. URL: http://journals.openedition.org/ etnografica/2532 ; DOI: https://doi.org/10.4000/etnografica.2532

\section{(c) (1) \&}

Etnográfica is licensed under a Creative Commons Attribution-NonCommercial 4.0 International License. 


\section{Procesos de revalorización patrimonial en el barrio de Alfama: el papel de los estudiantes Erasmus en la tematización de la ciudad}

\section{Daniel Malet Calvo}

Consideramos a los estudiantes del programa Erasmus como actores sociales implicados en dinámicas de movilidad transnacional y de producción global de sentido, así como en sus procesos urbanísticos concomitantes. En tanto que objetos de la antropología del turismo, presentamos el caso de un grupo de Erasmus en el barrio de Alfama, en Lisboa, cuyos procesos de diferenciación y de producción de la autenticidad conducirán a ciertos emprendedores locales a la identificación y explotación de nuevos recursos turísticos. Los jóvenes estudiantes, mediante una particular interpretación de los materiales simbólicos presentes en la construcción imaginaria de Lisboa, renuevan los términos de la atracción por el lugar, favoreciendo nuevos procesos de patrimonialización y capitalización socioespacial en el barrio de Alfama.

PALABRAS-CLAVE: antropología del turismo, programa Erasmus, Alfama, procesos de patrimonialización, bairrismo, tematización.

Patrimonial revaluation processes in Alfama neighbourhood (Lisbon): the role of Erasmus students in city thematization - Erasmus program students are regarded as social actors involved in medium term transnational mobility, and this feature has consequences on both global meaning production and on the dynamics of local urban processes. Taking it as an object of study within the anthropology of tourism, the dynamics of a group of Erasmus students of Alfama neighbourhood in Lisbon are analyzed. Their differentiation discourses and authenticity production processes have led local entrepreneurs to identify and explore new resources for tourism. Young students, through a particular interpretation of symbolic elements present in Lisbon's imaginary construction, have renewed the meanings of its sense of place, providing new heritagization processes and social-spatial capitalization in Alfama neighborhood.

KEYWORDS: tourism anthropology, Erasmus program, Alfama, heritagization processes, bairrismo, thematization.

MALET CALVO, Daniel (danielmalet@gmail.com) - Grup de Recerca sobre Exclusió i Control Socials (GRECS), Departament d'Antropologia Social i Cultural, Universitat de Barcelona, España; CIES-IUL, ISCTE - Instituto Universitário de Lisboa, Portugal. 


\section{EL PROGRAMA ERASMUS, ESTADO DE LA CUESTIÓN}

Los estudiantes del programa de intercambio universitario conocidos como Erasmus (homenaje al humanista de Rotterdam y acrónimo inglés de European Region Action Scheme for the Mobility of University Students) representan hoy un importante flujo de movilidad estudiantil transnacional, con notables implicaciones ideológicas, económicas e institucionales comprometidas en su funcionamiento. Son casi tres millones los estudiantes que han pasado por el Erasmus: desde los 3244 que se acogieron en el programa el año 1987, a los 250.000 del curso 2012, circulando entre 33 países - los 27 de la Unión más Croacia, Islandia, Liechtenstein, Noruega, Suiza y Turquía (European Comission 201 1). Ante la existencia de un fenómeno de movilidad de esta magnitud - que condiciona el mercado inmobiliario y la industria de servicios, además de generar numerosos procesos transnacionales de producción de sentido -, no podemos sino preguntarnos por la pertinencia de su análisis mediante los instrumentos teóricos proporcionados por la antropología del turismo. Ahora bien, ¿qué aproximaciones han sido ya producidas sobre los Erasmus desde las ciencias sociales en general?

Confrontándonos con la literatura generada hasta el momento, nos encontramos con que el programa Erasmus ha sido estudiado fundamentalmente por paradigmas institucionalistas y a través de metodologías eminentemente cuantitativistas. La primera de ellas - desde la óptica disciplinaria de las ciencias de la educación - es la evaluación del impacto de la movilidad estudiantil en la adquisición de competencias profesionales (Pinho 2002) o lingüísticas (Serrano, Llanes y Tragant 2011) y en la posterior integración laboral de los estudiantes (Teichler y Janson 2007). El programa también ha sido sometido a análisis en tanto que estrategia de internacionalización educativa por parte de las instituciones europeas (Antunes 2005; Teichler 2009). Tales aproximaciones - centradas en el programa en tanto que política pública - son quizás las que han generado el mayor volumen de literatura sobre los Erasmus, aportando en ocasiones fecundas y certeras críticas sobre el modelo Europeo de Educación Superior. En especial, se han examinado las pautas de desigualdad inherentes a la distribución diferencial de oportunidades que ofrece el programa, tanto entre países como entre estudiantes con un bajo nivel de renta (Bienefeld y Almqvist 2004; Souto-Otero 2008), demostrándose una significativa dependencia entre los niveles socioeconómicos de los estudiantes y su participación en los programas de intercambio (Messer y Wolter 2005). Ahora bien, en todos los estudios de caso consultados, en los grandes informes que genera o auspicia la Comisión Europea, y en los enfoques habituales de revistas como la European Journal of Education o la Journal of Studies in International Education, los Erasmus aparecen como meros objetos pasivos, indicadores del éxito o del fracaso de las políticas institucionales europeas. 
Otra aproximación habitual se centra en la construcción identitaria de la "ciudadanía europea", en tanto que adquirida y representada por los estudiantes a través de su propia experiencia transnacional (Streitwieser 2011). En este sentido, es interesante como el marco de circulación que propician los programas de intercambio promueve la generación de una élite de jóvenes europeos altamente cualificados y acostumbrados a la movilidad, entre los cuales se producen las cada vez más frecuentes uniones intra-europeas (Gaspar 2009; Favell 2008). Por contraste con estas relaciones amorosas transnacionales entre sujetos de alta instrucción, otros estudios tratan de establecer las causas de la inhibición de la movilidad estudiantil entre la juventud europea (Cairns y Growiec 2009), en ocasiones sin hacer alusión a los impedimentos económicos y sus efectos socioculturales, e incluso adoptando las concepciones reduccionistas e instrumentales de James Coleman o de Robert Putnam sobre el capital social (Portes 1998; Fine 2001).

Finalmente, tenemos la literatura "motivacional", que trata de establecer pautas y modelos sobre las decisiones de los estudiantes al escoger un destino (Llewellyn-Smith y McCabe 2008), al apostar por el aprendizaje de una lengua concreta (Drozdzewski 201 l) o al dirigir su atención hacia la educación superior en un país extranjero determinado (Kondakci 2011). Este tipo de estudios, donde aparecen ya valoraciones sobre índices y percepciones de satisfacción (Van't Klooster et al. 2008), o análisis sobre la concepción del aprendizaje vital y extra-académico en tanto que beneficio profesional (Teichler 2004), se emparentan ya con la literatura del educational travel en la antropología del turismo.

Ahora bien, estamos ante estudios marcados por evaluaciones cuantitativistas, de corte estadístico, o bien argumentaciones donde los discursos de los Erasmus no aparecen confrontados con sus prácticas ni con las condiciones de producción y reproducción de sus vidas cotidianas. Además, no encontramos análisis alguno sobre la especificidad de los procesos sociales concretos protagonizados por los estudiantes, ni su papel en tanto que actores sociales productores de sentido e implicados en las transformaciones y en los fenómenos derivados de su presencia en un país extranjero. Tanto es así que debemos alejarnos momentáneamente del fenómeno específico Erasmus para encontrar algún que otro estudio sobre estudiantes internacionales de intercambio, en la Tourism Review International de 2004, por ejemplo. En este mismo sentido, han sido publicados recientemente, en un número especial de la revista Anthropology in Action, algunos trabajos procedentes de un proyecto de investigación del que citaremos dos ejemplos: las vicisitudes de las familias, entrenadores y jóvenes canadienses comprometidos en el disfrute de una beca deportiva norteamericana (Dyck 2010) y la organización cognitiva y espacio-temporal de la experiencia del viaje de estudios por parte de jóvenes estudiantes canadienses en Australia (Barnick 2010). En tales estudios, donde se recalcan los aspectos relacionales, simbólicos y contextuales de la experiencia del desplazamiento, 
se trata ya la movilidad estudiantil como un objeto de la antropología, específicamente de la antropología del turismo.

\section{LOS ERASMUS Y LA ANTROPOLOGÍA DEL TURISMO}

La antropología del turismo, desde sus orígenes como especialización subdisciplinaria - o como encuentro interdisciplinar, si se prefiere (Tribe 1997; Mair 2006) -, ha explorado toda clase de relaciones y contextos inherentes al desplazamiento temporal de seres humanos, la generación de imágenes sobre los destinos y los procesos de transformación que en ellos tienen lugar (Smith 1989 [1977]; MacCannell 1999 [1976]; Cohen 1984; Crick 1989; Nash y Smith 1991). Si bien la literatura antropológica sobre el turismo puede ser presentada como una polarización entre los defensores y los detractores de la llamada "industria turística" (Jafari 2005), la revisión etnográfica de su "impacto" en contextos determinados revela la complejidad de los procesos turísticos, irreductibles a la interpretación unívoca (Neveling y Wergin 2009): un contexto de aculturación neocolonial, marcado por la mercantilización de la hospitalidad y el simulacro cultural; una ocasión para el empowerment de ciertas comunidades mediante la reinvención y el refuerzo de las identidades culturales locales; una representación de las relaciones de poder y dominación entre "países emisores" y "países receptores" de turistas; un mecanismo ritual de ruptura cognitiva y espacio-temporal con la rutina laboral de la vida cotidiana, por parte de unos viajeros empeñados en hallar una experiencia "auténtica"; una estrategia capitalista de penetración de nuevos mercados a través del discurso "desarrollista"; un marco relacional propicio para el rechazo, el refuerzo o la reformulación de los estereotipos sobre determinadas sociedades, etc. (Stronza 2001).

Sea como sea, entre los pocos textos consagrados a la antropología del turismo donde aparecen los Erasmus - y lo hacen a penas como una simple mención -, hay un punto en común: su inclusión como objeto de estudio llega en un momento de reconfiguración epistemológica de la disciplina (Nogués 2009: 48). Inmigrantes laborales, residentes extranjeros, emigrantes de retorno o estudiantes de intercambio configuran nuevas movilidades, ligadas tanto a la producción de imágenes del "destino", como a las consecuencias sobre la economía local, y donde turismo, estudios, migración y trabajo se intersectan mutuamente (Rice 2010). Estamos ante un momento de renovación disciplinaria, con la disolución de las antiguas oposiciones entre hosts y guests, y donde la astucia auto-reflexiva de la agencia y los procesos dialógicos se sobreponen al peso sistémico y dominante del negocio turístico. Cuando las nuevas movilidades, el consumo de imágenes, y la experiencia espacio-temporal del ocio no distinguen ya radicalmente a los turistas de los habitantes de la ciudad (Mavric y Urry 2009), ¿dónde quedan nuestros Erasmus? 
A pesar de la larga tradición historiográfica que sitúa el origen del turismo en el Grand Tour (Towner 1985; Brodsky-Porges 1981), solo recientemente han sido descritos los atributos del educational travel (Wood 2001; Ritchie 2003). A propósito del debate sobre sus motivaciones ("tourist first" tourists o "education first" tourists), ha quedado sobradamente demostrada la primacía por la búsqueda de nuevas experiencias vitales en un entorno extraño, por encima de las meramente académicas (Le Vacon 2009). Aprender, instruirse y vivir alejados de las ataduras de la cotidianidad, realizar actividades recreativas y descubrir el entorno visitado, se vuelve central para los estudiantes de intercambio, una categoría relativamente inexplorada dentro de la antropología del turismo (Llewellyn-Smith y McCabe 2008; Van't Klooster et al. 2008). Si bien las tradicionales tipologías de turistas distinguían las motivaciones e impacto de cada modalidad en una especie de péndulo que oscilaba entre el "turista de masas" y el "explorador pionero" (Burns 1999), el estudiante de intercambio escapa de ellas a través de dos características fundamentales: la relativa juventud de los sujetos y la duración extensiva de la estadía. Es por medio de estas peculiaridades que los estudiantes Erasmus se sobreponen al antiguo debate sobre la autenticidad entre turistas y viajeros (Cohen 1979; Wang 1999). En tanto que jóvenes, el proceso del viaje y la permanencia residencial imponen intensas y diversificadas modalidades de producción de subjetividad (Pais 1990; Jafari 1992), vinculadas a la función ritual del viaje y a la experiencia interestructural de su estadía (Graburn 1989 [1977], 2001; Turner y Turner 1978; Nash 1996: 39 y ss.).

Además, los Erasmus - como otros nuevos sujetos globales - no ocupan una posición central ni una posición periférica en la industria turística, ya no son actores diferenciados respecto al lugar donde residen, sino que participan de la producción y distribución de distinciones propia de la sociedad urbana concreta donde habitan (Bourdieu 1998). En este sentido debemos comprender su papel como agentes sociales activos en los procesos concretos en los que se insertan en el marco local, especialmente en lo que respecta a las dinámicas de revalorización y mercantilización del espacio ligadas a las transformaciones urbanas en curso (Franquesa 2011). Así, a los instrumentos teóricos de la antropología del turismo, debemos añadir la perspectiva de la literatura etnográfica consagrada a los procesos de patrimonialización y de gentrificación en los espacios centrales de las ciudades contemporáneas (Sieber 1997; Degen y García 2012). Este cruzamiento teórico y epistemológico debe guiar nuestra comprensión sobre la generación y circulación de imágenes patrimoniales entre los estudiantes Erasmus, así como su participación en la producción de la identidad del lugar: ¿qué relaciones se establecen entre el desembarque anual de un gran contingente de estudiantes de intercambio y los procesos de transición urbanística en la capital?, ¿qué incidencia real tienen los estudiantes Erasmus en el reciclaje de imágenes 
sobre la ciudad y en los procesos urbanísticos asociados a las operaciones de patrimonalización?

\section{LOS ERASMUS: UNA BREVE CARACTERIZACIÓN}

Entré por primera vez en contacto con un grupo de estudiantes Erasmus en Lisboa en el transcurso de mi segunda estadía en la ciudad, cuando me encontraba desarrollando mi investigación doctoral. Se trataba de un análisis etnográfico de las apropiaciones socioespaciales identificadas en la plaza de Rossio y sus aledaños, el espacio histórico más emblemático de la capital portuguesa y eje de la bipolarización morfológica de la ciudad. A través de la revisión de sus más variados aspectos, emergía el verdadero legado de la reconstrucción de la ciudad después del terremoto de 1755 por el Marquês de Pombal: la configuración político-cultural y simbólica de la identidad patrimonial lisboeta.

Fue en esta segunda estadía, entre abril y agosto de 2008, que acabé viviendo e integrándome entre un grupo particular de Erasmus, cuya relación específica con el espacio y el imaginario del barrio de Alfama - que bien pronto me llamaron la atención - constituyen el material de este texto. Más tarde, en las subsiguientes estadías que realizaba en Lisboa para continuar mi investigación, acababa siempre por recoger notas y realizar más etnografía que la que convenía sobre los Erasmus. Así, los datos y observaciones generales a los que vamos a hacer referencia a continuación corresponden a dos grupos de Erasmus con los que trabajé (en los cursos académicos 2008-2009 y 2009-2010) además de los de Alfama, así como a generalizaciones elaboradas a partir de la convivencia con estos grupos.

Según mi experiencia, los estudiantes Erasmus son actores sociales particulares y diferenciados en el contexto lisboeta en tanto que jóvenes extranjeros, estudiantes y residentes temporales; ahora bien, forman parte de la complejidad relacional de los contextos micro-locales donde viven, participando de los discursos y las prácticas de la sociabilidad urbana, de los procesos de capitalización socioespacial y de las dinámicas de producción de la identidad del lugar. Para establecer una primera tipología o diferenciación entre la vasta heterogeneidad que representan, debemos conocer y describir sistemáticamente los procesos sociales que envuelven su vida cotidiana: discursos, prácticas y condiciones de producción y reproducción de sus vidas en el nuevo contexto local; implicaciones y participaciones concretas en los procesos sociales y en las transformaciones de los contextos donde habitan; posición específica en la estructura social micro-local y hábitos de sociabilidad, agrupamiento y vecindad; etc.

El primer ámbito que debe ser explorado sistemáticamente es el encuadramiento de los estudiantes en las instituciones de la Universidad a un nivel administrativo, educacional y de ocio, ámbito primario de contacto y agrupamiento de los estudiantes extranjeros entre sí y con la sociedad local (facultades, clases, nacionalidades, aparejos de distinción y sistemas de afinidad). Un segundo 
nivel de integración y diferenciación viene determinado por los estilos de vida y las pautas de convivencia, agrupamiento y residencialidad, que organizarán su experiencia y su cotidianidad en el ámbito de la sociabilidad urbana general: búsqueda de vivienda, frecuentación de asociaciones o colectividades, espacios de ocio y grupos de amistad, ocupación del tiempo libre, etc. Por medio de estos fenómenos de distinción y afinidad, los estudiantes Erasmus se dirigen hacia contextos determinados (o participan en procesos sociales concretos), donde acaban implicados en dinámicas locales variadas; en algunas de ellas - como el caso que aquí presentamos - se van a dirimir aspectos de la revalorización patrimonial de la ciudad, así como procesos generales vinculados a las transformaciones del espacio urbano.

Sea como sea, tales pautas de agrupamiento y de diferenciación generan grupos muy diversificados y heterogéneos, a los que podríamos referirnos como "culturas Erasmus", en el sentido que muestran una participación diferenciada como agentes en la urdidura de las sociabilidades y procesos generales que tienen lugar en la ciudad. Ahora bien, a pesar de las distinciones centrífugas operadas por los actores sociales en sus contextos específicos (y que podemos apreciar en su intensa especificidad en el trabajo de campo etnográfico), es evidente que existe una fuerza centrípeta que efectúa un trabajo de homogeneización sobre las experiencias Erasmus. Se trata de la intensidad festiva y relacional que el programa Erasmus se empecina en estimular (y que, como veremos, los Erasmus de Alfama consideraban "vulgar"): la tutela por parte de alumnos locales mediante el programa "Buddy", las constantes welcome parties organizadas por las entidades oficiales y privadas dedicadas a los Erasmus, la gratuidad de acceso a la económica tarifa telefónica "Moche", la supuesta excepcionalidad académica tolerada para los Erasmus, etc. Todo está dispuesto para favorecer una progresión exponencial de las redes de conocidos, así como su confluencia recurrente en eventos y espacios de naturaleza sobre todo festiva: desde encuentros "privados" (casas Erasmus), pasando por el ocio y el consumo sectorial (fiestas Erasmus), hasta el encuentro con la población local (eventos de la ciudad, zonas de ocio, festivales, etc.).

En estos espacios los diferentes grupos de Erasmus construyen su condición como sujetos colectivos en respuesta a su excepcional volatilidad: sus miembros comparten la condición intersticial de su extranjería ("estar aquí y ahora"), viviendo una vida disoluta con la característica aceleración y concentración emocional promovida por parte de los organizadores del programa. Grupos relacionales de excepción, viajeros sentimentales contemporáneos, los Erasmus parecen desarrollar una especie de fetichismo espacial con aquellos lugares que contribuyen a transformar, como veremos a continuación. Al fin y al cabo su condición - y la que parece ser la consecuencia más notable de su presencia - es la de una especie de invasión estacional que remueve y altera las instituciones, servicios y mercados locales, especialmente en los espacios de mayor centra- 
lidad. Es en este sentido que podemos decir que los Erasmus, por supuesto, forman parte del caldo de cultivo frecuentemente descrito en el proceso de sustitución de poblaciones y de revalorización del suelo urbano conocido como gentrification (Lees, Slater y Wyly 2008). Ahora bien, nuestro objetivo en este texto es presentar a un grupo particular cuya interacción con los fenómenos patrimoniales y de tematización urbana presenta una sutilidad característica.

Si hasta el momento nos hemos referido a los Erasmus en general a partir de nuestra experiencia con tres grupos distintos, en las siguientes secciones - y si no se indica lo contrario - nos referiremos con "Erasmus" al grupo particular del que nos encargamos en este texto, esto es, al grupo de Alfama. La metodología concreta se centró en la recogida de datos, observaciones y descripciones sobre la vida cotidiana de los Erasmus y su relación con el barrio, fruto de una convivencia intensa con el grupo, complementada por la elaboración abierta de preguntas en el contexto "natural" de las cenas de grupo y en múltiples conversaciones informales. En suma, la fundamentación metodológica se basa en un seguimiento íntegro de la experiencia del viaje de los Erasmus, que la literatura de la antropología del turismo ha llamado "pre-etnografía" (Michaud 1995: 682).

\section{ALFAMA, EL PÁTIO Y LOS ERASMUS}

El barrio de Alfama, situado en la mitad oriental del casco antiguo de la ciudad de Lisboa, representa mejor que ninguno los atributos asociados a los bairros antigos de la capital portuguesa. ${ }^{1}$ Caracterizado por una población popular con una escasa cualificación sociolaboral, Alfama presenta asimismo algunos cuadros técnicos y profesionales con gran influencia sobre la proyección patrimonial del barrio y algunos de sus procesos sociales (Costa 1999: 223 y ss.). La relativa estabilidad residencial y la composición morfológica de una malla urbana densa e intrincada facilitan los mecanismos de reproducción de las relaciones de proximidad, marcadas por la inmediatez e intensidad de las relaciones vecinales que constituyen su "cultura popular urbana" (Costa 1999: 302 y ss.). Una serie de procesos endógenos y exógenos de estructuración, integración y afirmación sociocultural contribuyen a la construcción y reproducción del bairrismo: identidad de barrio articulada por discursos y dinámicas relacionales intensas, y centrada en un fuerte sentimiento de pertenencia microlocal (Cordeiro 2003).

En este enclave urbano, Alfama, y durante mi segunda estadía en la ciudad de Lisboa (entre abril y agosto del 2008), me alojé durante 11 días en el Típico

I Los bairros antigos son aquellos que, a veces independientemente de la antigüedad de su trazado, contienen - para la política cultural y patrimonial de las autoridades municipales - las más genuinas expresiones sociales y urbanísticas de la ciudad. Todos ellos son también bairros populares o típicos, esto es, espacios considerados como propios de las clases populares urbanas características de la ciudad de Lisboa, y que anualmente desfilan en las marchas dos santos populares. Ver Cordeiro (2003). 
Hostel, ${ }^{2}$ un establecimiento para jóvenes turistas cool regentado por un par de emprendedores portugueses. Encajado en medio del barrio más "pitoresco" de la ciudad, en un pátio poblado por personajes rebosantes de "autenticidade", 3 el hostel se ofrece por su disposición, mobiliario y diseño, a un público joven anglófono, travellers cosmopolitas amantes del confort, pero enemigos de las grandes estructuras turísticas. La organización del espacio y los turnos de recepción (cubiertos por las parejas de los propietarios) favorecían la proximidad con los anfitriones, generando un ambiente de confraternización generalizada: era muy habitual encontrar en los sofás de recepción a los propietarios y a sus parejas charlando relajadamente con los huéspedes, a veces entre risas y copas. El hostel se encontraba en un flanco del Pátio das Cantigas, ejemplo de arquitectura típica de los barrios antiguos de Lisboa: un patio central organizaba a su alrededor pequeñas viviendas a ras de suelo, dando acceso a dos escaleras que llevaban a sendas galerías con pisos en altura. Todas las ventanas y caminos de entrada al complejo de viviendas confluían en el pátio, que encerraba el lugar sobre sí mismo generando un espacio colectivo entre los domicilios. Por aquel entonces, las unidades domésticas del pátio - una veintena - se caracterizaban por una fuerte asimetría en las clases de edad representadas: una gran parte de su población estaba altamente envejecida, sobre todo mujeres solas, y contaba con una proporción muy baja de parejas con hijos, así como de jóvenes solos, tanto portugueses como Erasmus. Desde un rincón, completaba el conjunto un hostel en pleno proceso de expansión, pero todavía encerrado tras unas puertas metálicas.

Yo me encontraba a la espera de ser alojado en un apartamento del pátio, como había sido acordado desde Barcelona con Pedro y Adolfo - los socios del hostel -, para seguir mis investigaciones sobre la plaza de Rossio. Pero el propietario del pátio, el Sr. Tiago, un portugués que además regentaba una taberna en la zona de Rato, se mostraba reacio a alquilar más viviendas del pátio para el crecimiento del hostel. Pedro criticaba el conservadurismo y la "escasa visión empresarial" del Sr. Tiago, y fantaseaba con la "atracción incomparable" que pronto ejercería el hostel, un reducto anglófono, cómodo y tranquilo situado en el corazón mismo del "zoo humano" que es Alfama, desde donde conocer las maravillas "pitorescas" del barrio, como la cercana Feira da Ladra. Adolfo, el otro socio del hostel, hablaba del negocio con una expresividad astuta y sugestiva, describiendo las dificultades de los pequeños empresarios en el sector turístico a causa del absentismo de la Câmara Municipal. Con un ademán seguro en sus gestos, presentaba el negocio a través de una precisa caracterización de su público: un perfil creciente de jóvenes de clase media con intereses culturales

2 Todos los nombres propios han sido sustituidos por seudónimos, incluidos el nombre del hostel y el del pátio, al que he dado el nombre del célebre filme de Francisco Ribeiro, O Pátio das Cantigas (1942). 3 En cursiva y entre comillas se encuentran aquellas categorías emic pertenecientes a la construcción patrimonial de la identidad bairrista lisboeta, tal y como se expresa tanto oficialmente como en los discursos de los emprendedores locales y de los Erasmus. Ver Cordeiro (2003). 
que trascienden lo museificado, y que buscan puntuar la fiesta nocturna con edificantes paseos por evocadoras y románticas callejuelas. Sin problemas de dinero, huyen de los lujos excesivos y buscan un ambiente de cómoda familiaridad, que les asegure ser conducidos por sus anfitriones a los lugares más auténticos y desconocidos de un barrio cuya potencialidad turística está por explotar.

Sin el apartamento prometido, finalmente me instalé en una de las pequeñas viviendas Erasmus de la explanada del pátio, a escasos metros de las puertas del hostel, acogido - mientras buscaba algo definitivo - por una catalana y un italiano (Montse y Maurizio). En la explanada había otras dos viviendas alquiladas por Erasmus: Nadine (francesa de origen portugués) y Alfred (alemán de Berlín). Me encontraba ya en el pátio, núcleo emblemático de un grupo de Erasmus particular entre los que descubriría la revalorización del espacio por medio de la relectura de los imaginarios locales.

\section{LA INELUDIBLE INGENUIDAD DE LA TEMATIZACIÓN}

Los Erasmus de Alfama se habían agrupado siguiendo dos orientaciones: los contactos primarios (clases en la facultad y en el curso de portugués) y la residencialidad (vecindario y compañeros de piso), ejes que se articulaban entre sí y mediante las vinculaciones generadas por la lengua, la procedencia nacional y otras afinidades transmitidas por aparejos simbólicos de distinción. En efecto, la mayoría se habían conocido en la Universidade Nova de Lisboa, donde estudiaban licenciaturas de ciencias sociales o de humanidades, y su descripción podría sintetizarse bastante si decimos que se movían entre gustos bohemios, posiciones izquierdistas y espiritualidades New Age. Al contingente Erasmus restringido del pátio, habituales de Alfama y amistades de la Universidad (entre 7 y 14 individuos estables), se unían varios locales y Erasmus conocidos en diferentes circunstancias y eventos, constituyendo - al final del período de estancia - el total alcanzable de la red extensa de habituales (unos 30). Cabe destacar que la excepcionalidad relacional propia de los Erasmus (mixtura de clases, inversión de roles sociales, intensos sentimientos de compañerismo y afinidad, facilidad por hacer amigos) refuerza un sentimiento colectivo de integración social - equiparable con la communitas de Turner (1988) - que se extiende durante toda la estadía en el extranjero y que posibilita la liberación de la rutina ordinaria de procedencia, tal y como ha sido ya señalado para el turismo en general (Graburn 1989 [1977]).

La afirmación de la vida comunitaria del grupo, asentada sobre un sistema de relaciones socialmente reguladas, se articulaba mediante dos órdenes de temporalidad. El primero era marcado por la cotidianidad de los intercambios, los préstamos y la circulación de bienes entre las unidades domésticas Erasmus, que sustentaba un sistema de reciprocidad con continuos ciclos de circulación de objetos, visitas inesperadas y cadenas de favores. Las continuas comidas 
conjuntas favorecían este intercambio de objetos: los instrumentos de cocina eran una auténtica propiedad comunal, cuya dispersión propiciaba una y otra vez la celebración de nuevas comidas y cenas grupales. Entre las viviendas Erasmus circulaban además, y con frecuencia, piezas de ropa, libros, plantas, mobiliario y hasta instrumentos musicales. El segundo orden de temporalidad tenía que ver con la organización de encuentros extraordinarios y excepcionalidades festivas: cumpleaños, cenas de fin de semana, visitas de amigos de los Erasmus, despedidas. Éstas contaban con la presencia del grupo extenso, pero eran organizadas sobre todo en las viviendas o en la explanada del pátio, así como en los miradores de Graça o de Alfama, contando siempre con la concurrencia de instrumentos musicales y botellas de alcohol. Cabe decir que la urgencia e intensidad con la que se organizan y viven los acontecimientos del grupo - sean eventos ordinarios o extraordinarios -, corresponde a la consciencia de la caducidad final del estado interestructural, propia de la experiencia ritual del viaje (Nash 1996: 39-44).

La construcción social del tiempo "de ocio" (Santos 1999) revelaba una idiosincrasia específica, propensa al consumo cultural alternativo (Crew Hassan, Bacalhoeiros, Chapitô), los movimientos sociales (Colectivo Gaia, Centro Social da Mouraria), el culto al bairrismo local (Tejo Bar, Típica de Alfama) y significativas actividades extra-universitarias (circo, capoeira y somaterapia). Este perfil dibujaba un elocuente rechazo al modelo de ocio nocturno representado por el Bairro Alto y las discotecas del Cais y de las Docas, centro neurálgico del ocio joven y de la cultura Erasmus oficial en Lisboa. ${ }^{4}$ Esta voluntad de distinción con los hábitos y las geografías de otros Erasmus - y sobre todo con la "vulgaridad" de los turistas -, viene acompañada por una actitud vital dirigida a la fusión con la autenticidad del espíritu local, marcada por muchos momentos de retiro silencioso, de paseos solitarios e inspiradores por el barrio, e incluso por la meditación. El centro ceremonial de tales dispositivos de distinción se encontraba, en efecto, en la vida comunitaria del Pátio das Cantigas.

La explanada del pátio ante las viviendas definía el espacio de sociabilidad cotidiana del grupo restringido - facilitando una severa relajación de los niveles de privacidad entre las unidades domésticas de los Erasmus - y era el lugar predilecto del encuentro extraordinario para el grupo extenso. Su apropiación constante en términos de permeabilidad entre el espacio público y el privado era frecuentemente imaginada y verbalizada como un comportamiento derivado de la adaptación a la vida típica de Alfama, una especie de mímesis con la auténtica sociabilidad bairrista. En efecto, el grupo extenso - Erasmus pero

4 Por "cultura Erasmus oficial" me refiero a aquella que viene promovida directamente por los organismos públicos y privados dedicados a los Erasmus, como ESN (Erasmus Students Network) o EOL (Erasmus Organization Lisboa), entidades que ofrecen descuentos a los Erasmus para disfrutar de ocio barato en circuitos determinados de bares y discotecas, frecuentemente en el Bairro Alto y en las Docas. 
también locales - compartía una representación particular y muy extendida sobre la ciudad de Lisboa: las formas, las instituciones y los ritmos de sociabilidad, ciertamente dinámicos y rebosantes de conflicto, eran interpretados como estáticas actitudes de resistencia a la modernidad, lo que merecía sus inmediatas simpatías. El encantamiento por esa Lisboa atrapada en el tiempo tenía su apoteosis en las pintorescas callejuelas de los bairros antigos y en la cruda autenticidad de sus gentes, sustancias imaginarias en las que centraban su apetencia espiritual. La fascinación del grupo por estas representaciones se centraba en Alfama, con el pátio en el epicentro de la sociabilidad y el sosiego vital con el que emulaban y se igualaban a los locales, interaccionando con ellos.

Lo cierto es que el contacto con los vecinos del pátio será una constante en la vida cotidiana de los Erasmus: Los saludos rutinarios a las ancianas que vivían a ras de suelo, asomadas durante horas en las ventanas a ver quem passa; los arrebatos juguetones de Duque - el perro de los vecinos de arriba - que irrumpía continuamente en las viviendas Erasmus; las constantes visitas de la vecina brasileña; las sesiones de limpieza de alfombras por parte de las vecinas que descendían a la explanada; el espacio común para tender la ropa, compartido con las velhotas alfameñas; incluso episodios de ayuda vecinal mutua como el rescate de un gato atrapado en un patio interior, o el auxilio a una señora mayor durante un colapso respiratorio hasta la llegada de la ambulancia. Los conflictos con los vecinos de arriba por algunas cenas en el pátio hasta tarde se vieron compensados por emotivas despedidas de los mismos cuando los Erasmus, a final de curso, empezaron a abandonar la explanada. El pátio era proyectado por el grupo como un espacio de autenticidad e identificación con el barrio, un campo real donde tenían lugar encuentros e interacciones genuinas entre Erasmus y vecinos, un lugar donde las sociabilidades de unos se confundían con las de los otros.

No se trata de negar las dimensiones reales de estas relaciones, sino de resaltar sus términos imaginarios, sus proyecciones ideológicas: El pátio era el escenario donde los Erasmus devenían alfameños. En un ejercicio imaginario de identificación con el barrio, construían su experiencia mediante una mezcla entre el misticismo espiritual de la New Age - que traían consigo -, y una invocación constante de las representaciones patrimoniales sobre el barrio, que circulaban repetidamente en el canon turístico lisboeta y en los discursos y prácticas del bairrismo. A través de tales elementos - tan presentes en las imágenes oficiales sobre la ciudad - los Erasmus habían absorbido indirectamente los contenidos propios de la olisipografía de época romántica: un "género compuesto de anotaciones históricas y míticas, arquitectónicas y urbanísticas, etnográficas y periodísticas sobre la ciudad de Lisboa, en especial de sus aspectos más antiguos o considerados tradicionales" (Cordeiro y Costa 1999: 79). ${ }^{5}$

5 La olisipografía fue la responsable por la construcción folclorizante de la ciudad de Lisboa en el marco del proyecto decimonónico de patrimonialización nacional. Ver Ramos (2003) y Castelo Branco (1980). 
Los Erasmus captaban in situ la materia prima de las representaciones patrimoniales y de sus condiciones de reproducibilidad cotidiana, asumiéndolas como propias en el marco del pátio. La sociabilidad bairrista (Costa 1999), la evocación de los "grupos etnoprofesionales" (Cordeiro 2001: 12) y las fiestas de Lisboa componen el tríptico alfacinha ${ }^{6}$ que tiene su apoteosis en las marchas dos santos populares, una escenificación folclorizante producto de la domesticación de las fiestas populares urbanas durante el Estado Novo (Melo 2003). Las marchas de cada barrio desfilan hoy en una competición que exalta el espíritu bairrista como elemento constitutivo de la identidad lisboeta, a medio camino entre la afirmación microlocal de las coletividades que lo organizan en cada barrio y la instrumentalización municipal de las fiestas (Carvalho 1991). ${ }^{7}$ Asimismo, las proyecciones Erasmus sobre la idiosincrasia lisboeta beben también de la fuente común: los estereotipos que alimentan las estrategias identitarias (Bastos 2000), las autorrepresentaciones historiográficas (Matos 2002; Mattoso 1998) y la construcción mítica del carácter portugués en general (Leal 2000; Sobral 2004). Dentro de este canon, una cierta "historiografía de la fatalidad" (dominio filipino, ultimatum de Inglaterra, terremoto de 1755) acompañado de productos socioculturales específicos (sebastianismo, saudade, Quinto Império) han permitido a ciertos autores interpretar los problemas del presente en base a representaciones simplificadas del pasado: el llamado problema del "exceso de diagnóstico" (Santos 2011).

Sea como fuere, lo cierto es que los Erasmus se convierten en actores implicados en la manipulación de representaciones e imaginarios locales precedentes, en agentes vinculados a la generación de valor patrimonial a escala transnacional (Smith 2006). Así, como veremos a continuación, los elementos preexistentes - el canon de la olisipografia y del portuguesismo (Matos 2002: 133) - experimentarán operaciones creativas de alteración, recombinación y desplazamiento, al asumir los Erasmus estos atributos como sus rasgos adoptivos, y al contraponerlos a los de otros actores sociales en el marco de procesos de diferenciación microlocal en el pátio.

\section{LA BATALLA POR EL PÁTIO}

En efecto, los Erasmus articulaban sus antagonismos imaginarios identificando su propia cotidianidad con el temperamento y el estilo de vida local, que subsumían bajo el lema "hacer vida de patio". Para el grupo, el ritmo vital sosegado y contemplativo que los locales desplegaban en sus deambulaciones por el barrio, o la lánguida sociabilidad de los vecinos de Alfama en los bares,

\footnotetext{
6 Alfacinhas (lechuguitas) es el gentilicio que hace referencia a los habitantes de Lisboa.

7 Las coletividades son asociaciones voluntarias de base territorial, de raíz deportiva, religiosa u otra, estructuradas y estructurantes en la vida colectiva de los bairros lisboetas. Ver Cordeiro (1995: 16).
} 
eran producto de una especie de preferencia espiritual, un gusto por la serena improvisación de sus vidas. Sin embargo, tales impresiones correspondían frecuentemente a realidades locales como el desempleo de larga duración, o a la soledad de la vejez en el aislamiento viario de un barrio de colina. En este sentido el ambiente sonoro característico de Alfama, marcado por aquella calma ruralizante tan apreciada por los Erasmus y los turistas, se debe a las restricciones de entrada de vehículos, un conflicto abierto con fuertes resistencias locales. A pesar del boicot continuo a las máquinas de acceso condicionado de vehículos, o a las pintadas y carteles en el barrio ("A EMEL está a matar Alfama"), ${ }^{8}$ los Erasmus preferían ignorar el fenómeno.

Lejos de las visiones complejizadoras de la realidad del barrio, solamente un conflicto era visible para los Erasmus: la presencia contaminante del hostel y de los turistas que desfilaban por el pátio. En efecto, la construcción de la particularidad del grupo era operada siempre por contraste con formas más efímeras o menos "auténticas" de vivir el barrio y la ciudad, principalmente la de los otros Erasmus y sobre todo la de los turistas, quienes "no se relacionan con los vecinos" ni "aprecian la autenticidad" de Alfama. La relación con el vecindario y con amistades locales, la extensión de su estadía o el conocimiento de la lengua, favorecían la construcción subjetiva de su cotidianidad como experiencia “auténtica" (Wang 1999), en oposición a la vulgaridad inherente al consumo "rápido e inconsciente" de un lugar. Nuestros Erasmus demostraban ser tan "anti-turistas" como los back-packers (cfr. Barnick 2010: 21). Mención aparte merecía el hostel, que rompía con la "armonía" del pátio a un nivel estético, pero sobre todo moral: sus pobladores ignoraban y perturbaban el estilo de vida de Alfama, su realidad local, profanando con efímeras y ruidosas presencias el carácter "sagrado" de sus rutinas. Al concebir el barrio como una reserva natural de encantadores indígenas, los encontramos radicalizando la visión conservacionista que ya habían afirmado los gestores del hostel: Alfama como "zoo humano".

Como es obvio, las prácticas cotidianas de los Erasmus y algunos de sus discursos distaban de una observancia estricta de los principios que guiaban la vida comunitaria del pátio, en tanto que emulación de la "autenticidad" de Alfama. Sus conductas reales y su implicación en ciertas actividades mostraban una distancia muy relativa con la presencia del hostel: usaban los equipamientos culturales y los servicios terciarios con asiduidad, consumían y producían imágenes - sobre todo fotografía - con un enfoque semejante al de los turistas (Urry y Crawshaw 1995), e incluso pedían permiso para usar la red Wi-Fi del hostel. Ello no obsta para que los eramus construyan su identidad

8 EMEL, Empresa Pública Municipal de Estacionamento de Lisboa. Las asociaciones de residentes y de comerciantes culpan al organismo de estar marchitando el comercio local y de favorecer el aislamiento del barrio. 
mediante una contraposición explícita con los turistas, de quienes se burlaban con frecuencia cuando éstos entraban en el pátio buscando el hostel: Cargados y agotados por las colinas, eran conducidos hacia alguna de las reducidísimas viviendas Erasmus del pátio, como si fuera su alojamiento. La intención, claro, era ver reflejada - a través de la cara de horror de los huéspedes - la diferencia sustantiva entre la vida en el pátio y en el hostel. Pero resultó no ser tan diferente. En pocos meses los propietarios del hostel alquilaban la casa de Montse y Maurizio, instalando ahí un apartamento para turistas. Aparecían también bancos, que permitían la estadía contemplativa en el pátio, desde donde podía verse la decoración elegida para el nuevo apartamento del hostel: dos estatuas de buda contemplaban desde el interior a los últimos Erasmus del pátio, que les devolvían - a través de la ventana - una mirada consternada, de incomprensión y horror ante el reflejo deformado de sí mismos.

Así, actores sociales aparentemente antagónicos para los procesos de producción del espacio parecen mostrar la costura de sus contigüidades e influencias mutuas: los estudiantes Erasmus estimulan las transformaciones del lugar, organizan la industria y ponen en circulación sofisticadas imágenes del destino, convirtiéndose en productores de la identidad local, en agentes implicados en los procesos de valorización local.

\section{PATRIMONIALIZACIONES RECIENTES EN ALFAMA}

No es extraño el orgullo que siente la Comisión Europea por su programa más popular: Los estudiantes Erasmus refuerzan los procesos de construcción identitaria europea, estimulan las economías locales agitando con su presencia el mercado inmobiliario o el sector del ocio nocturno, y además facilitan la internacionalización de la economía (Amit 2010). Pero es que además, en tanto que viajeros espoleados por una mirada romántica, identifican - a través de sus procesos de subjetivación - las potencialidades inscritas en las prácticas y en las imágenes locales. Su conocimiento directo del terreno y su aptitud adaptativa visibilizan activos de valor para la subsunción al capital de nuevos espacios. Pero los Erasmus no son los únicos actores sociales implicados en este proceso: la identificación y movilización de recursos es aprovechada por los pequeños emprendedores para lanzar nuevos productos al mercado, en el contexto de la revalorización del espacio y sus nuevos sentidos patrimoniales.

En Lisboa, operadores turísticos y Estado disponen las condiciones infraestructurales para la industria y difunden la imagen de la ciudad en guías y rutas oficiales, materiales promocionales y folletos explicativos, escondiendo bajo el mármol y el bronce otras lisboas, conflictivas y discrepantes (Carvalho 2006). Ahora bien, en Alfama - como en todos los bairros populares - los guardianes de los dispositivos simbólicos de representación son las coletividades, a partir de las cuales se realiza la escenificación de la autenticidad bairrista: las marchas 
dos santos populares. La formación histórica de tal evento nos muestra la estrategia de integración social de las autoridades municipales, al hacer concurrir a algunas de las coletividades - en tanto que interlocutores microlocales privilegiados - (Cordeiro 1995: 132-139) en la representación ideológica de la Lisboa hegemónica. La recreación imaginaria de la singularidad de cada bairro en las marchas pone en funcionamiento conocidos elementos provenientes del canon olisipográfico, una "materia prima" compartida por el gobierno, la industria, los turistas y los locales en la representación de la "cultura local" (Nogués 2009).

Es en este terreno de juego simbólico, difuminada la antigua dicotomía entre hosts y guests, cuando encontramos la intersección microlocal entre los pequeños emprendedores turísticos - que exhiben la antigua planta del pátio fotocopiada de la obra del olisipógrafo Norberto de Araújo - y los Erasmus, quienes - sin conocer los detalles patrimoniales del espacio -, se convierten en "mediadores culturales" (Salazar 2006: 113 -1 14), al actualizar la atracción por el bairro en términos novedosos. Así, en el ambiente microlocal del pátio, los Erasmus fueron actores significativos para la definición de las atracciones comercializables del hostel y para el moldeamiento de sus consumidores: el hostel salía finalmente al pátio, y vendía bairrismo.

\section{EPÍLOGO: SUTILES SUBSUNCIONES}

No es la primera vez que se advierte el papel de los estudiantes como agentes activos en los procesos de revalorización y transformación urbana - Darren P. Smith (2005) habla de studentification - ni siquiera para el caso de los presuntamente "alternativos" o hasta "radicales" (Lloyd 2002), a quienes se encuentra en numerosos casos penetrando y señalando la potencialidad de los barrios degradados, acompañando estilos de vida locales (Rodrigues 2010). Hoy mismo, en el barrio lisboeta de Mouraria, bienintencionados artistas acompañan las tareas higienizadoras de las autoridades municipales, instalando sus ateliers y organizando sus workshops. Parece como si la concurrencia de "vanguardias del gusto" - en clave creativa o en tono radical - fuera un requisito, un factor urbanístico estructurante para los procesos de transformación en sectores urbanos en vías de tematización.

En Alfama el reciclaje de valores patrimoniales realizado a través de la producción de diferencias entre los Erasmus (una especie de "economía emocional del espacio") era aprovechado por actores sociales con mayor poder de intervención sobre el mercado inmobiliario y la promoción turística. Más allá de la sobre-demanda de ocio y suelo que representan los Erasmus en general, el grupo de Alfama constituía un suporte sutil y creativo para la subsunción del espacio al capital, dibujando los contornos de una agenda oculta involuntaria: la de un saber pionero e impetuoso que parece hundir sus raíces en los toscos - aunque ingeniosos - ademanes de la civilización capitalista. 


\section{BIBLIOGRAFÍA}

AMIT, Vered, 2010, "Student mobility and internationalisation: rationales, rhetoric and 'institutional isomorphism", Anthropology in Action, 17 (1): 6-18.

ANTUNES, Fátima, 2005, "Globalização e europeização das políticas educativas: percursos, processos e metamorfoses”, Sociologia, Problemas e Práticas, 47: 125-143.

BARNICK, Heather, 2010, "Managing time and making space: Canadian students' motivations for study in Australia", Anthropology in Action, 17 (1): 19-29.

BASTOS, José Gabriel Pereira, 2000, Portugal Europeu: Estratégias Identitárias Inter-Nacionais dos Portugueses. Oeiras, Celta Editora.

BIENEFELD, Stefan, y Johan ALMQVIST, 2004, "Student life and the roles of students in Europe”, European Journal of Education, 39 (4): 429-441.

Bourdieu, Pierre, 1998, La Distinción: Criterio y Bases Sociales del Gusto. Madrid, Taurus. BRODSKY-PORGES, Edward, 1981, "The Grand Tour: travel as an educational device, 1600-1800", Annals of Tourism Research, 8 (2): 171-186.

BURNS, Peter, 1999, An Introduction to Tourism and Anthropology. Londres y Nueva York, Routledge.

CAIRNS, David, y Katarzyna GROWIEC, 2009, "Learning insularity? Social capital, social learning and staying at home among European youth". Lisboa, ISCTE-IUL, CIES e-Working Paper n. ${ }^{\circ}$ 81/2009, <http://www.cies.iscte.pt/destaques/documents/CIES -WP8 1 CairnseGrowiec.pdf>.

CARVALHO, Francisco Avelino, 2006, "O lugar dos negros na imagem de Lisboa”, Sociologia, Problemas e Práticas, 52: 87-108.

CARVALHO, Ruben de, 1991, "A vertente política e a vertente popular das festas de Lisboa", en Festas de Lisboa: Relatório da Comissão Consultiva das Festas de Lisboa de 1990. Lisboa, Livros Horizonte, 26-55.

CASTElO BRANCO, Fernando, 1980, Breve História da Olisipografia. Amadora, Instituto de Cultura Portuguesa.

COHEN, Erik, 1979, "A phenomenology of tourist experiences", Sociology, 13 (2): 179-201.

COHEN, Erik, 1984, “The sociology of tourism: approaches, issues, and findings", Annual Review of Sociology, 10: 373-392.

CORDEIRO, Graça Índias, 1995, Um Bairro no Coração da Cidade: Um Estudo Antropológico sobre a Construção Social de Um Bairro Típico de Lisboa. Lisboa, ISCTE, tese de doutoramento.

CORDEIRO, Graça Índias, 2001, “Trabalho e profissões no imaginário de uma cidade: sobre os ‘tipos populares' de Lisboa”, Etnográfica, V (1): 7-24.

CORDEIRO, Graça Índias, 2003, "Uma certa ideia de cidade: popular, bairrista e pitoresca”, Sociologia (revista da Faculdade de Letras da Universidade do Porto), 13: 185-199.

CORDEIRO, Graça Índias, y António Firmino da COSTA, 1999, "Bairros: contexto e intersecção", en Gilberto Velho (org.), Antropologia Urbana: Cultura e Sociedade no Brasil e em Portugal. Rio de Janeiro, Jorge Zahar Editor, 58-79.

COSTA, António Firmino da, 1999, Sociedade de Bairro: Dinâmicas Sociais da Identidade Cultural. Oeiras, Celta Editora.

CRICK, Malcolm, 1989, "Representations of international tourism in the social sciences: sun, sex, sights, savings, and servility”, Annual Review of Anthropology, 18: 307-344. 
DEGEN, Mónica, y Marisol GARCÍA, 2012, “The transformation of the 'Barcelona model': an analysis of culture, urban regeneration and governance", International Journal of Urban and Regional Research, 36 (4): 1022-1038.

DROZDZEWSKI, Danielle, 2011, "Language tourism in Poland", Tourism Geographies: An International Journal of Tourism Space, Place and Environment, 13 (2): 165-186.

DYCK, Noel, 2010, “Going south: Canadians' engagement with American athletic scholarships", Anthropology in Action, 17 (1): 41-54.

EUROPEAN COMISSION, 2011 , Erasmus: Facts, Figures and Trends. The European Union Support for Student and Staff Exchanges and University Cooperation in 2009/2010. Luxemburgo, Publications Office of the European Union.

FAVELL, Adrian, 2008, Eurostars and Eurocities: Free Movement and Mobility in an Integrating Europe. Oxford, Blackwell.

FINE, Ben, 2001, Social Capital versus Social Theory: Political Economy and Social Science at the Turn of the Millennium. Londres y Nueva York, Routledge.

FRANQUESA, Jaume, 2011 , “'We've lost our bearings': place, tourism, and the limits of the 'mobility turn'”, Antipode, 43 (4): 1012-1033.

GASPAR, Sofia, 2009, “Mixed marriages between European free movers”. Lisboa, ISCTE-IUL, CIES e-Working Paper n. ${ }^{\circ}$ 65/2009, <http://www.cies.iscte.pt/destaques/documents/ CIES-WP65_Gaspar.pdf>.

GRABURN, Nelson, 1989 [1977], “Tourism: the sacred journey”, en Valene L. Smith (org.), Hosts and Guests: The Anthropology of Tourism. Filadélfia, University of Pennsylvania Press, 21-36.

GRABURN, Nelson, 2001, "Secular ritual: a general theory of tourism", en Valene Smith y Maryann Brent (orgs.), Hosts and Guests Revisited: Tourism Issues of the 21st Century. Nueva York, Cognizant Communication Corporation, 42-50.

JAFARI, Jafar, 1992, "Significado sociocultural y educacional del turismo de juventud", Papers de Turisme, 8-9: 39-46.

JAFARI, Jafar, 2005, "El turismo como disciplina científica”, Política y Sociedad, 42 (1): 39-56. KONDAKCI, Yasar, 2011 , "Student mobility reviewed: attraction and satisfaction of international students in Turkey”, Higher Education, 62 (5): 573-592.

LEAL, João, 2000, Etnografias Portuguesas (1870-1970): Cultura Popular e Identidade Nacional. Lisboa, Publicações Dom Quixote.

LEES, Loretta, Tom SLATER, y Elvin K. WYLY, 2008, Gentrification. Londres y Nueva York, Routledge/Taylor and Francis Group.

LE VACON, Vincent, 2009, Motivaciones e Impacto Turístico de los Estudiantes Erasmus: El Caso de la Ciudad de Madrid. Bournemouth University, Université de Savoie y Universidad Rey Juan Carlos, tesis de Master of Arts in European Tourism Managment.

LLEWELLYN-SMITH, Catherine, y Vivienne S. McCABE, 2008, "What is the attraction for exchange students: the host destination or host university? Empirical evidence from a study of an Australian university", International Journal of Tourism Research, 10 (6): 593-607. LLOYD, Richard, 2002, "Neo-bohemia: art and neighborhood redevelopment in Chicago", Journal of Urban Affairs, 24 (5): 517-532.

MAcCANNELL, Dean, 1999 [1976], The Tourist: A New Theory of the Leisure Class. Berkeley y Los Angeles, CA, University of California Press.

MAIR, Heather, 2006, "The potential of interdisciplinarity for leisure research", Leisure Sciences, 28 (2): 197-202. 
MATOS, Sérgio Campos, 2002, "História e identidade nacional: a formação de Portugal na historiografia contemporânea”, Lusotopie, 2002 (2): 123-139.

MATTOSO, José, 1998, A Identidade Nacional. Lisboa, Editora Gradiva.

MAVRIC, Misela, y John URRY, 2009, “Tourism studies and the new mobilities paradigm”, en Tazim Jamal y Mike Robinson (orgs.), The Sage Handbook of Tourism Studies. Londres, Sage Publications, 646-659.

MELO, Daniel, 2003, "As marchas populares: a encenação da cidade de Lisboa", en Salwa El-Shawan Castelo-Branco y Jorge Freitas Branco (orgs.), Vozes do Povo: A Folclorização em Portugal. Oeiras, Celta Editora, 307-321.

MESSER, Dolores, y Stefan C. WOLTER, 2005, "Are student exchange programmes worth it?”, IZA Discussion Paper n. ${ }^{\circ}$ 1656, Bonn, Institute for the Study of Labor (IZA).

MICHAUD, Jean, 1995, "Questions about fieldwork methodology", Annals of Tourism Research, 22 (3): 681-684.

NASH, Dennison, 1996, Anthropology of Tourism. Oxford, Pergamon.

NASH, Dennison, y Valene SMITH, 1991, "Anthropology and tourism", Annals of Tourism Research, 18 (1): 12-25.

NEVELING, Patrick, y Carsten WERGIN, 2009, "Projects of scale-making: new perspectives for the anthropology of tourism”, Etnográfica, 13 (2): 315-342.

NOGUÉS, Antonio Miguel, 2009, "Genealogía de la difícil relación entre antropología social y turismo", Pasos: Revista de Turismo y Patrimonio Cultural, 7 (1): 43-56.

PAIS, José Machado, 1990, "A construção sociológica da juventude: alguns contributos", Análise Social, XXV (105-106): 139-165.

PINHO, Maria de Fátima Duarte de Almeida, 2002, Mobilidade Transnacional e Competências Profissionais: Um Estudo de Caso com Alunos Envolvidos no Programa Socrates-Erasmus, Lisboa, Universidade Nova de Lisboa, tese de mestrado.

PORTES, Alejandro, 1998, "Social capital: its origins and applications in modern sociology", Annual Review of Sociology, 24: 1-24.

RAMOS, Rui, 2003, "A ciência do povo e as origens do estado cultural”, en Salwa El-Shawan Castelo-Branco, y Jorge Freitas Branco (orgs.), Vozes do Povo: A Folclorização em Portugal. Oeiras, Celta Editora, 25-35.

RICE, Kathleen, 2010, “'Working on holiday': relationships between tourism and work among young Canadians in Edinburgh", Anthropology in Action, 17 (1): 30-40.

RITCHIE, Brent, 2003 (org.), Managing Educational Tourism. Clavedon, UK, y Buffalo, NY, Channel View Publications.

RODRIGUES, Walter, 2010, Cidade em Transição: Nobilitação Urbana, Estilos de Vida e Reurbanização em Lisboa. Lisboa, Celta Editora.

SALAZAR, Noel, 2006, "Antropología del turismo en países en desarrollo: análisis crítico de las culturas, poderes e identidades generados por el turismo", Tabula Rasa: Revista de Humanidades, 5: 99-128.

SANTOS, Ana, 1999, Inter-Rail: A Odisseia em Comboio. Oeiras, Celta Editora.

SANTOS, Boaventura de Sousa, 201 1, Portugal: Ensaio contra a Autoflagelação. Coimbra, Edições Almedina.

SERRANO, Raquel, Àngel LLANES, y Elsa TRAGANT, 201 1, "Analyzing the effect of context of second language learning: domestic intensive and semi-intensive courses vs. study abroad in Europe", System, 39 (2): 133-143. 
SIEBER, Timothy, 1997, "Urban tourism in revitalizing downtowns: conceptualizing tourism in Boston, Massachusetts", en Erve Chambers (org.), Tourism and Culture: An Applied Perspective. Albany, State University of New York Press, 59-76.

SMITH, Darren P., 2005, “Studentification': the gentrification factory?", en Rowland Atkinson y Gary Bridge (orgs.), Gentrification in a Global Context: The New Urban Colonialism. Londres y Nueva York, Routledge, 72-89.

SMITH, Laurajane, 2006, Uses of Heritage. Londres y Nueva York, Routledge.

SMITH, Valene L. (org.), 1989 [1977], Hosts and Guests: The Anthropology of Tourism, Filadelfia, University of Pennsylvania Press.

SOBRAL, José Manuel, 2004, "O Norte, o Sul, a raça, a nação: representações da identidade nacional portuguesa (séculos XIX-XX)”, Análise Social, XXXIX (171): 255-284.

SOUTO-OTERO, Manuel, 2008, "The socio-economic background of Erasmus students: a trend towards wider inclusion?", International Review of Education, 54 (2): 135-154.

STREITWIESER, Bernhard, 201 1, "Erasmus mobility students and conceptions of national, regional and global citizenship identity", The Roberta Buffett Center for International and Comparative Studies, Center for Global Engagement Working Paper Series, n. ${ }^{\circ}$ 1 1-001, <http://www.cics.northwestern.edu/documents/workingpapers/CGE_11-001 Streitwieser.pdf $>$.

STRONZA, Amanda, 2001, "Anthropology of tourism: forging new ground for ecotourism and other alternatives", Annual Review of Anthropology, 30: 261-283.

TEICHLER, Ulrich, 2004, “Temporary study abroad: the life of Erasmus students”, European Journal of Education, 39 (4): 395-408.

TEICHLER, Ulrich, 2009, "Internationalisation of higher education: European experiences", Asia Pacific Education Review, 10 (1): 93-106.

TEICHLER, Ulrich, y Kerstin JANSON, 2007, “The professional value of temporary study in another European country: employment and work of former Erasmus students”, Journal of Studies in International Education, 11 (3-4): 486-495.

TOWNER, John, 1985, "The Grand Tour: a key phase in the history of tourism", Annals of Tourism Research, 12 (3): 297-333.

TRIBE, John, 1997, “The indiscipline of tourism”, Annals of Tourism Research, 24 (3): 638-657.

TURNER, Victor, 1988, El Proceso Ritual: Estructura y Antiestructura. Madrid, Taurus.

TURNER, Victor, y Edith TURNER, 1978, Image and Pilgrimage in Christian Culture: Anthropological Perspectives. Nueva York, Columbia University Press.

URRY, John, y Carol CRAWSHAW, 1995, "Turismo e consumo visual”, Revista Crítica de Ciências Sociais, 43: 47-68.

VAN'T KLOOSTER, Erik, Jeroen VAN WIJK, Frank GO, y Johan VAN REKOM, 2008, “Educational travel: the overseas internship", Annals of Tourism Research, 35 (3): 690-711.

WANG, Ning, 1999, "Rethinking authenticity in tourism experience", Annals of Tourism Research, 26 (2): 349-370.

WOOD, Chris, 2001, "Educational tourism”, en Norman Douglas, Ngaire Douglas y Ros Derrett (orgs.), Special Interest Tourism: Contexts and Cases. Brisbane, John Wiley \& Sons, 188-211. 